\title{
Assessing Levels of Brand Recognition by Children Aged 3 to 5 Years
}

\author{
Ezeni Brzovska and Dimitar Kovachevski
}

\begin{abstract}
The paper aims to present the design and interpretation of an empirical study whether young children have ability to form mental representations of logos and recognize brands. Brand logos can serve as a perceptual cue that identifies a product as one children are familiar or unfamiliar with. The research is design to measure brand logo recognition by subjects aged 3 to 5 years. The findings demonstrated higher recognition rates of brand logos for products that are targeted directly to children compared to adult's brands. Results indicate that young children are capable of recognizing brands.
\end{abstract}

Keywords - adults brands, brand recognition, children brands.

\section{INTRODUCTION}

The paper is organized as follows: first the key literature on children and brand recognition is briefly reviewed, followed by methodology. The methodology of the empirical research is discussed and the main findings are interpreted. The paper ends by suggesting avenues for future research on children symbolism, and a brief discussion of the implications of this work for practitioners.

The mainstream marketing literature on children's understanding of brands is emphasized almost exclusively by Piagetian developmental cognitive psychology mode [1] , [2]. Piaget's theory of cognitive development framework comprise of four main stages: sensorimotor (birth to two years), preoperational (two to seven years), concrete operational (seven to eleven years), and formal operational (eleven through adulthood). Great differences are evident in the cognitive abilities and resources available to children at these stages and characteristics of each stage are essential for brands' persuasive intent to position certain products. Past research, consistent with the traditional theory of cognitive development, suggests that sophisticated symbolism understanding is absent until somewhere between 7 and 11 years [3]. Brand symbolism understanding is defined as an understanding of the meaning attributed to a brand name These findings are suggesting that brand symbolism understanding does not develop until 7 to 11 years of age and that immature

Ezeni Brzovska is Associate Professor at the Faculty of economics Skopje, Ss. Cyril and Methodius University in Skopje, Blvd. Goce Delchev 9V,1000 Skopje, Republic of North Macedonia.

Dimitar Kovachevski, is Associate Professor at the School of Business Economics and Management at University American College Skopje, Boulevard III Makedonska Brigada 60, 1000 Skopje, Republic of North Macedonia. cognitive capacity of preoperational children limits them to processing only individual elements of brand information and that their egocentric orientation to the world restricts any understanding of the intentions of others who might use brands for expressing individual purposes. Piagetian stages encompass broad age groupings and little is known about the effects of individual differences on performance outcomes on different age groups. Given a recent call for research considering individual differences [4] and given the shortcomings of past research mentioned as follows, the present research is designed to measure brand recognition among children aged 3 to 5 years following McAlister and Cornwell classification.

Brand recognition plays an important role in children's brand symbolism understanding; since it does not make sense that a child could understand the social symbolism of a brand they cannot recognize [5]. Reference [5] suggests certain indications why certain brands might be in focused and recognized by young children while other brands will escape their attention. The study claims that brands that are consumed more frequently or are marketed directly to children will have a greater chance to be recognized by young children.

Several studies have found that young children are capable of recognizing brands logos. Reference [6] used verbal questionnaire to assess the recognition of eight consumer symbols. The research has confirmed that influences of developmental and environmental factors in socialization of consumers begin at an early age. Young children have limited knowledge, reasoning powers, and reading skills compared to adults and therefore media has a powerful influence on consumer socialization. Other study analyzed preschool mothers' perceptions of whether popular commercial symbols (e.g., Mickey Mouse or Barney) or brand names influenced on children's clothing preferences and buying intentions. Findings indicated that consumer socialization of children begins at an early age examining selected aspects of consumer socialization of children from the ages of 3-6 within the theoretical framework of consumer socialization [7].

Reference [8] studied the recognition level of twenty two brand $\log o$ s by children aged 3 to 6 years. The research demonstrated that children had high recognition of the children's brand logos ranging from $91.7 \%$ for the Disney logo. The paper reveals that recognition level has been increased by age for each product categories. 
The way in which young children form brand awareness and associations, have implications for their lifelong relationships to material possessions [9].

It was confirm that children as young as 2-3 years old are able to recognize brands and the ability to think about them symbolically is developing with age as children become aware of the social meanings of the brand [10]. Consequently children learn to relate to brand names at an early age, recognizing brand names in different communication places. It is assumed that brand recognition may play a role in the development of materialistic tendencies and the way they value material possessions [11].

Concerns over the rising level of materialism among young children are evident in many studies. Materialism increases from middle childhood to early adolescence and declines from early to late adolescence. Reference [12]. shows how materialistic values develop in childhood and confirmed that self-esteem is an important mediator of age differences and a significant cause of changes in expressions of materialism.

The influence of social and cultural contexts within which young children develop their symbolic understanding of brands plays vital role in understanding brand symbolism. Communication messages are gaining increasingly early brand recognition among young children. Marketing efforts for childoriented product strive to employ a branding approach in most of the communication messages, focusing on equation that product equals fun and happiness [13].

Findings expose that brand symbolism understanding starts as early as two years, and increases with age throughout the pre-school years. Children are more likely to prefer branded products if they are exposed to more television and have less critical parental communication style [14].

The previous studies have confirmed the validity and ability of young children to have mental representation for certain brands. Children's recognition of child-oriented brands is found to be significantly greater versus recognition of brands that are marketed primarily to teens and adults.

The present study investigates whether 3- to 5-year-old children have higher recognition level for children brands compared to brands targeted primarily to adults. Therefore following proposition is tested:

H1: Children's recognition of brand logos will differ as a function of the brand's target segment. Recognition will be higher for children's brands than compared to adults brands.

\section{METHODOLOGY}

The present research was employed to investigate whether children aged 3 to 5 years are capable of recognizing brands from different product types. The participant sample comprised of 35 children ( 15 boys, 20 girls) aged 3 years to 5 years. The stimuli were twenty one brands logo cards representing 14 product categories.
Analysis of a qualitative study involving children aged 3 to 5 indicates the complex and multi-dimensional roles that brands play in children's everyday lives.

Children were instructed to match twenty one brand logo cards with one of complementary product images positioned on a wall board. Twenty-one logos were separately tested, including those representing children's products and adult products. To each child was explained that it would be playing game by matching product image cards with brand logos (Figure 1).

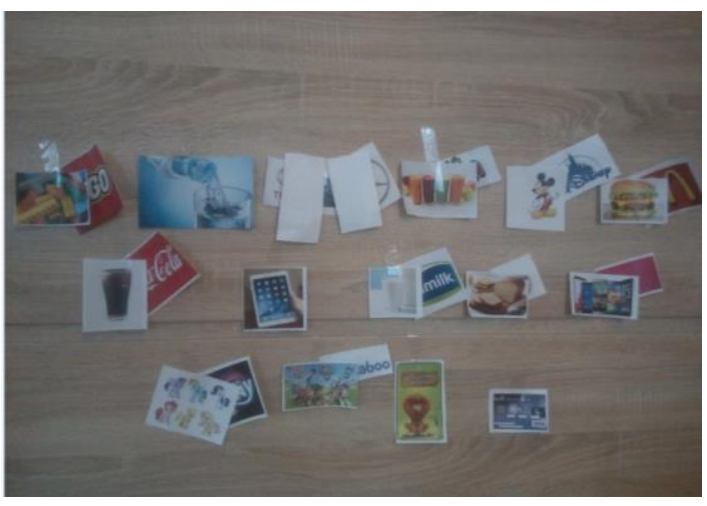

Fig. 1 Sample of Wall Board for Brand Logo and Product Images cards

Mentor did not give any additional instructions or demonstration of matching brand logo cards. The child was handed a brand logo card to match by immediately approaching to wall board (Figure 2). After placing the card on the board (whether correct or incorrect), the child received encouragement.

In individual sessions, brand logo cards were shown to the child one at a time and then he or she would place it next to the product image card. For the known products, the child would immediately match the brand, but when he faced uncertainty he or she would ask questions to mentor. The mentor will answer "What ever you think is right". Consequently the child took second brand card and placed it right next to the product image. The same procedure followed for all the twenty one brand cards. Afterword all the received data from the brand cards were evaluated and analyzed in order to define brand recognition level for each child. Responses were graded as either correct (grade of 1) or incorrect (grade of 0), and a score was calculated by summarizing the correct values for each logo. For each children and adults brands grades were transformed into recognition level based on the percentage of correct matches. 


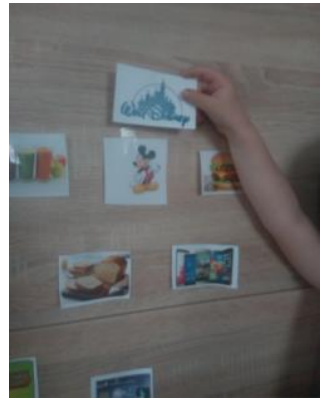

Fig. 2 Sample of Children's Responses to Brand Representation Task

Recognition was measured by having the subjects match twenty one brand logo cards to one of the products images on a game board (Table I). Table I presents children's average brand recognition level. The study confirm finding from previous research [8] that children have higher recognition level for children brands. H1 is confirmed. Consistent with $\mathrm{H} 1$, young children are more successful at recognizing children's brands than adults $\square$ brands.

TABLE I

PERCENTAGE OF BRAND RECOGNITION ACROSS DIFFERENT PRODUCT TYPES

\begin{tabular}{cllr} 
Product category & \multicolumn{1}{c}{ Logo } & $\begin{array}{c}\text { Compatible product } \\
\text { response }\end{array}$ & Recognision rate \\
\hline \hline Childrens brands & Lego & Building blocks & $93.8 \%$ \\
& Little Pony & Unicorn & $91.6 \%$ \\
& Walt Disney & Michey Mouse & $89,4 \%$ \\
& Pikaboo chanel & Cartoon characters & $78,9 \%$ \\
& Kras & Chocolate & $78,6 \%$ \\
& & & \\
Adult brands & Apple & Ipad & $75,5 \%$ \\
& Coca Cola & Glass of cola & $73,2 \%$ \\
& Burger King & Hamburger & $65,2 \%$ \\
& McDonalds & Hamburger & $63,3 \%$ \\
& Kia & Automobile & $62,7 \%$ \\
& Ford & Automobile & $58,3 \%$ \\
& Toyota & Automobile & $56,9 \%$ \\
& Tutunska Banka & ATM & $56,8 \%$ \\
& Viva & Glass of juice & $54,7 \%$ \\
& Komercijalna Banka & ATM & $54,7 \%$ \\
& Bitolsko Mleko & Glass of milk & $54,6 \%$ \\
& Bucen Kozjak & Glass of milk & $52,7 \%$ \\
Stopanska Banka & ATM & $34,7 \%$ \\
Mercedes & Automobile & $34,5 \%$ \\
& Telekom & Mobile phone & $34,2 \%$ \\
Zito Luks & Bread & $23,0 \%$ \\
\hline
\end{tabular}

Stated research has shown that young children aged 3-5 years are capable of recognizing brands. Among the brands, the most frequently recognized was a toy brand Logo (93.80\%), followed by Little Pony cartoon (91,6\%). Among adults brand the highest recognition level has Apple brand $(75,7 \%)$ and lowest Zito Luks (23\%). The foreign adult's brands have greater recognition grates compared to domestic ones. Regarding automobile and financial product categories children demonstrated greater recognition level for brands owned by their parents. For instance, the child manifested awareness for Kia as automobile brand, only because that brand was their family car and had wrong answers for all the others automobile brands. The same situation was evident among financial brands for the certain bank logo.

Consequently, the stimuli that children are exposed to, are from great importance for the awareness and potential future loyalty for certain brans.

TABLE II

BRAND LOGO RECOGNITION RATES BY YEARS OF AGE FOR CHILDREN'S AND ADULT'S BRANDS

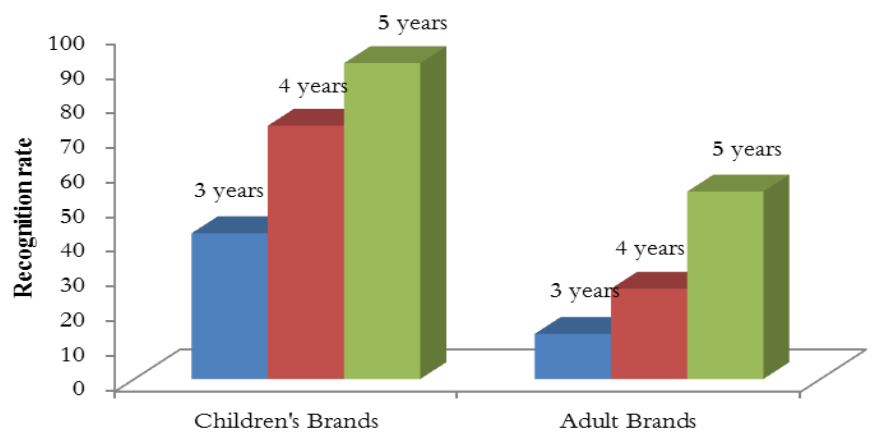

Table II shows recognition rates by age for children and adults brands. Logo recognition was highly associated with the subject's age. The recognition level of the children brands among 5 years children was $91 \%$ compared to $42 \%$ among 3 years old ones. Decreased recognition level was evident for adults brands, where only $13 \%$ of 13 years old children match correctly the defined brand logos. It was expected that will more developed cognitive abilities the awareness of brand logos will be increased. Nonetheless, the influence of social and cultural factors should not be discounted in understanding brand recognition among young children.

Therefore, we have additionally investigated the perception of children for their positive or negative association related for the previously selected brands.

.For the each brand logo card children were ask to place the card above two emoticons (the good and the bad ones). The intention of the task was to analyze which brands are perceived from children perspective as positive ones versus negative. This task allowed us to observe the reaction and opinion of children they hold for certain brands. The children evaluated correctly answered brands logos, only for the products that they have demonstrate brand knowledge..

All the brands were perceived as positive ones, expect for Coca cola which was identified as negative ones for 21 children. Certain empirical studies interpret the roles that brands play in the everyday lives, where the children designated brands as "cool" or "uncool" [15], [16].These studies addressed brand symbolism as deeply gendered, 
stressing that some brands could be emotionally indicted to the extent of becoming the objects of hatred or adoration.

\section{CONCLUSION}

Researching children recognition of brands offers a great possibility for academics and practitioners to understand the effects of brand logos in the lives of today's children, employing a more informed marketing approach. The ability to recognize brands from different product categories contribute for great insights in children's consumer decisionmaking skills. In the present research all the children demonstrated familiarity with the presented brands logos.

The study design relied on the ability of children to match cards picturing brand logos to products images on a game board. When analyzed by product type, the level of recognition of children brands was greater compared to adults brand logos. The recognition rates of Lego and Apple were highest in their respective product types. It was concluded that recognition rates increased with age. $91 \%$ of 5-year-old children correctly matched brand logos compared with $42 \%$ of 3-year-old children.

The present findings are also consistent with prior conclusions that young children are able to recognize brand logos and names [5] - [7].Clearly, for young children, brand recognition is emerging with age. Consistent with H1, young children were found to be more likely to recognize children's brands than brands that are targeted primarily to adults.

Children's knowledge of brand logos is most likely the result of their exposure to communication stimuli. Young children have developed a very keen sense of the social meaning and image, whether positive or negative, associated with certain types of products and brand names.

It was also confirmed that that children more frequently recognize the brands with which they have the most experience. For instance, children immediately recognize certain automobile brands because children see the brand logos each time they travel with or see the family owned car.

A further factor that might distinguish between the extents to which children's versus adults $\square$ brands are memorable could be children's experience with integrated communication stimuli. Brands for which children are the primary target segment will be marketed more aggressively to children. Consequently, the children's brand recognition will be increase when messages are tailored to elicit children's attention [5]. Children aged 3 to 5 years old understand, and recognized brand logos, but this is only initial research that should be studied further. The limitation of this study is that the subjects were a convenience and small sample.

Although the purpose of this research was to determine whether 3- to 5-year-old children's have brand knowledge for product logos, the intention is to extend the study with cognitive ability, executive functioning, or theory of mind. Understanding of children brand recognition is prerequisite for assessing brand representation ability and brand symbolism understanding among $3-5$ year children.

\section{REFERENCES}

[1] J. Piaget, "Piaget's theory", 1970 In P. H. Mussen (Ed.), Carmichael's manual of child psychology,pp. 703-732, New York: Wiley.

[2] J. Piaget, "General problems of the psychological development of the child", in Tanner, J.M. and Elders, B. (Eds), Discussions on Child Development: Proceedings of the World Health Organisation Study Group on Psychological Development of the Child, 1960

[3] D.R. John, "Consumer socialization of children: a retrospective look at twenty-five years of research", Journal of Consumer Research, Vol. 26, pp. 183-213, 1999

https://doi.org/10.1086/209559

[4] L.J. Moses and DA. Baldwin, "What can the study of cognitive development reveal about children's ability to appreciate and cope with advertising?",Journal of Public Policy \& Marketing, vol. 24, no.2, pp. 186-201, 2005.

https://doi.org/10.1509/jppm.2005.24.2.186

[5] A. R. McAlister and T. B. Cornwell, "Children's brand symbolism understanding: Links to theory of mind and executive functioning", Psychology \& Marketing, vol. 27, no.3, pp. 203-228, 2010. https://doi.org/10.1002/mar.20328

[6] L. E. Derscheid, Y. H. Kwon and S.R. Fang, “ Preschoolers' socialization as consumers of clothing and recognition of symbolism", Perceptual and Motor skills, vol.82(3_suppl), pp.1171-1181, 1996. https://doi.org/10.2466/pms.1996.82.3c.1171

[7] J.L. Haynes, D.C. Burts, A. Dukes and R Cloud, "Consumer socialization of preschoolers and kindergartners as related to clothing consumption", Psychology \& Marketing, vol.10, no.2, pp. 151-166, 1993.

https://doi.org/10.1002/mar.4220100207

[8] P.M. Fischer, M. P. Schwartz, J.W. Goldstein and T.H. Rojas, “ Brand logo recognition by children aged 3 to 6 years: Mickey Mouse and Old Joe the Camel", Jama, vol. 266, no.22, pp. 3145-3148, 1991. https://doi.org/10.1001/jama.266.22.3145

[9] H. Dittmar, "Material and consumer identities", Handbook of Identity Theory and Research, Springer, New York, NY, pp. 745-769, 2011. https://doi.org/10.1007/978-1-4419-7988-9_31

[10] G. B. Achenreiner and D. R. John, "The meaning of brand names to children: A developmental investigation", Journal of Consumer Psychology, vol 13 no. 3, pp. 205-219, 2003. https://doi.org/10.1207/S15327663JCP1303_03

[11] L. Watkins, R. Aitken, K. Robertson, M. Thyne and J. Williams, “Advertising's impact on pre-schoolers' brand knowledge and materialism", International Journal of Consumer Studies, vol. 40, no. 5, pp. 583-591, 2016. https://doi.org/10.1111/ijcs.12303

[12] L.N. Chaplin and D. Roedder John, "Growing up in a material world: age differences in materialism in children and adolescents", Journal of Consumer Research, vol. 34, no. 4, pp. 480-493, 2007. https://doi.org/10.1086/518546

[13] S.M. Connor, "Food-related advertising on preschool television: building brand recognition in young viewers." Pediatrics 118 , no. 4, pp.1478-1485, 2006.

https://doi.org/10.1542/peds.2005-2837

[14] L. Watkins, R. Aitken, M. Thyne, K. Robertson and D. Borzekowski, "Environmental influences on pre-schooler's understanding of brand symbolism", Marketing Intelligence and Planning, vol. 35, no.7:,pp.907-22, 2017. https://doi.org/10.1108/MIP-11-2016-0211

[15] A. Nairn, C. Griffin and P. Gaya Wicks, "The Simpsons are cool but Barbie'sa minger: the role of brands in the everyday lives of junior school children", University of Bath, Bath. 2006.

[16] A. Nairn, C. Griffin and P. Gaya Wicks, "Children's use of brand symbolism: A consumer culture theory approach." European Journal of Marketing, vol. 42, no. 5/6, pp. 627-640, 2008 https://doi.org/10.1108/03090560810862543 